\title{
Tendril Coiling in Grapevine: Jasmonates and a New Role for GABA?
}

\author{
Jaiana Malabarba ${ }^{1,2} \cdot$ Michael Reichelt $^{3} \cdot$ Giancarlo Pasquali $^{1} \cdot$ Axel Mithöfer $^{2}$ (D)
}

Received: 31 January 2018 / Accepted: 9 April 2018 / Published online: 27 April 2018

(c) The Author(s) 2018

\begin{abstract}
Grapevine (Vitis vinifera L., Vitaceae) belongs to the genus Vitis, and is characterized as a vine due to the presence of tendrils, which are located opposite to leaves. Tendrils are thigmo-responsive organs, able to carry out delicate mechanosensory responses upon touch and related stimuli. These organs are an adaptation of the plant to climb with the help of support to higher places and finally remain at a position with favorable light quality. In previous studies on Bryonia dioica (Cucurbitaceae), phytohormones of the jasmonate class were identified as the endogenous hormone signals to initiate coiling of the tendrils. Strikingly, this is still the only example for jasmonate-induced tendril coiling. In grapevine, three compounds (12-oxo-phytodienoic acid, jasmonic acid (JA), and JA isoleucine conjugate) of the jasmonate class were found at higher concentrations in non-coiled tendrils when compared with coiled ones. Upon treatment with phytohormones, we could confirm the activity of jasmonates on tendril coiling in grapevine. However, not jasmonates but a non-proteinogenic amino acid, $\gamma$-aminobutyric acid (GABA), was detected to accumulate in grapevine tendrils at significantly higher levels than in all other tissues, independent of their coiling status. For GABA we detected a significant, transient positive effect on tendril coiling. Use of a GABA synthesis blocker, 3-mercaptopropionic acid, caused reduced GABA- but not JA-induced coiling scores. No additive effect of JA plus GABA was detectable on the tendrils' coiling score. Thus, for grapevine, our data demonstrate a strong activity of jasmonates in tendril coiling induction even without mechanical stimuli and, furthermore, the data also suggest that GABA can independently promote tendril coiling.
\end{abstract}

Keywords $\gamma$-Aminobutyric acid · Jasmonic acid · Vitis $\cdot$ Tendril $\cdot$ Coiling

\section{Introduction}

From ancient times until today, grapevines have had a significant and intricate relation with mankind (This et al. 2006). These species, mainly from the Vitis genus, have a high agronomical importance and are consumed worldwide in natura and are appreciated as a divine drink: wine

Electronic supplementary material The online version of this article (https://doi.org/10.1007/s00344-018-9807-x) contains supplementary material, which is available to authorized users.

Axel Mithöfer

amithoefer@ice.mpg.de

1 Graduate Program in Cell and Molecular Biology, Biotechnology Center, Federal University of Rio Grande do Sul, Porto Alegre, Brazil

2 Department of Bioorganic Chemistry, Max Planck Institute for Chemical Ecology, Jena, Germany

3 Department of Biochemistry, Max Planck Institute for Chemical Ecology, Jena, Germany
(Lacirignola and Digiaro 1999). The grapevine family, Vitaceae, is one of the plant families described as vines due to a peculiar plant organ known as the tendril. Grapevines were classified by Darwin as tendril-bearers-type plants because their tendrils are long, slender, and filiform structures (Darwin 1865). These specific organs are adapted for climbing on a support object or host plant (Bowling and Vaughn 2009). This allows the plant to use stable structural supports, finally being able to grow in various ecological niches and also to reach sunlight (Isnard and Silk 2009).

Tendrils might have different evolutionary backgrounds depending on the plant family. In Vitis, meristematic protuberance primordia, which are formed by the terminal and axillary bud meristems - give rise to both grapevine tendrils and inflorescences (Pratt 1971; Srinivasan and Mullins 1979). For that reason, grapevine tendrils are morphologically homologous to inflorescences. This was elegantly demonstrated by treating grapevine tendrils with cytokinins, which converted them into inflorescences and bunches, showing its evolutionary 
background and the potential of tendrils to become reproductive organs (Srinivasan and Mullins 1979).

Tendrils are highly sensitive and can quickly coil around objects in response to mechanical stimuli (Braam 2004; Fukano and Yamawo 2015). This is due to their thigmoresponsive capability, promoting a directional (thigmotropism, for example, grapevine) or non-directional (thigmonasty, for example, Bryonia dioica) growth movement, which occurs as a mechanosensory response to a touch stimulus (Jaffe et al. 2002). The coiling mechanism of the tendril is classified into three main movements: (1) circumnutation, a movement increasing the probability to contact supports; (2) contact coiling, in which the stimulated tendril coils around a support; and (3) free coiling, in which the tendril develops helical coils along its axis. This last step allows the plant to get closer to the support (Jaffe and Galston 1968).

The coiling response appears to be mediated by phytohormones. Many studies characterized the importance of phytohormones in tendril coiling based on the Cucurbitaceae plant B. dioica (for example, Falkenstein et al. 1991; Weiler et al. 1993). The phytohormones mainly described in tendril coiling include jasmonates and auxin (Blechert et al. 1999; Stelmach et al. 1999; Engelberth 2003). Applying methyl jasmonate (MJ) or jasmonic acid (JA) was sufficient to induce tendril coiling in B. dioica even in the absence of mechanical stimuli (Falkenstein et al. 1991). The JA-induced response in tendril coiling is not rapid, starting after a lag-phase of several hours (Weiler et al. 1993). Additional studies suggested that the JAprecursor, 12-oxo-phytodienoic acid (OPDA), might be the endogenous signal transducer, not JA (Weiler 1997; Stelmach et al. 1999). However, JA-Ile as the most active jasmonate was not known at that time. All those studies showed the importance of jasmonates for tendril coiling - at least in B. dioica; interestingly, tendrils of Pisum sativum do not respond (Engelberth 2003). To our knowledge, $B$. dioica is still the only plant in which jasmonates were shown to induce tendril coiling.

Here, we aimed to study whether grapevine tendril coiling is also influenced by phytohormones, in particular jasmonates. We further analyze a role for GABA in the coiling process of this organ. Therefore, we determined the levels of various stress-related phytohormones and GABA in different grapevine organs with a focus on coiled and non-coiled tendrils. In addition, we performed experiments with grapevine tendrils to analyze the role of JA and GABA in the tendril coiling process.

\section{Materials and Methods}

\section{Plant Material}

We performed the experiments in two vineyards. The first one is located close to the city of Freyburg, Germany $\left(51^{\circ} 14^{\prime} 51.3^{\prime \prime} \mathrm{N} 11^{\circ} 40^{\prime} 53.9^{\prime \prime} \mathrm{E}, \sim 110 \mathrm{~m}\right.$ above sea level), and the second one is located in Bento Gonçalves, Brazil ( $29^{\circ} 09^{\prime} 44^{\prime \prime} \mathrm{S} 51^{\circ} 31^{\prime} 50^{\prime \prime} \mathrm{W}, \sim 640 \mathrm{~m}$ above sea level). The Gutedel cultivar, also known as Chasselas, was chosen for the experiments. On both sites the temperature on the vineyards was around $25-28{ }^{\circ} \mathrm{C}$. The plants were in the reproductive stage between 5 and 7 years old. The grapevines were at the pre-anthesis and fruit-set stage at the time of harvest, due to slightly different phenological development between the different plants. Nevertheless, all bunches were sampled at the fruit-set stage. Samples of leaves $(n=7)$, bunches $(n=7)$, branches $(n=7)$, and tendrils (coiled and non-coiled, $n=10$ each) (Supplementary Fig. 1) were collected in liquid nitrogen and kept at $-80^{\circ} \mathrm{C}$ until further analysis. For the tendril coiling assay, non-coiled tendrils were cut at the tendril's base with a small scissor.

\section{Extraction and Quantification of Phytohormones}

We analyzed the following compounds: JA; cis-(+)-OPDA; JA-L-isoleucine conjugate (JA-Ile), 12/11-hydroxy-JA (OH-JA), 12/11-hydroxyl-JA-L-isoleucine (OH-JA-Ile), and 12-carboxy-JA-L-isoleucine (COOH-JA-Ile). Around $250 \mathrm{mg}$ of fresh tissue from either leaves, bunches, branches, and tendrils (coiled and non-coiled) were frozen in liquid nitrogen, ground, and weighed for phytohormones analysis. The extraction procedure and determination of JA and JAIle were carried out as described before (Vadassery et al. 2012; Scholz et al. 2017) with small changes. In this study, a different mixture of labeled jasmonates was used as the internal standard. Instead of $15 \mathrm{ng}$ of JA- $\left[{ }^{13} \mathrm{C} 6\right]-$ Ile conjugate used in the previous study, $60 \mathrm{ng}$ of $\mathrm{D}_{6}$-JA-Ile (HPC Standards GmbH, Cunnersdorf, Germany) was used. Additionally, the 60 ng of 9,10- $\mathrm{D}_{2}-9,10$-dihydro JA was replaced by $60 \mathrm{ng}$ of $\mathrm{D}_{6}$-JA (HPC Standards $\mathrm{GmbH}$, Cunnersdorf, Germany). Phytohormones were quantified on an API 5000 LC-MS/MS system (Applied Biosystems, Darmstadt, Germany). Because it was observed that both the $\mathrm{D}_{6}$-labeled JA and $\mathrm{D}_{6}$-labeled JA-Ile contained $40 \%$ of the corresponding $\mathrm{D}_{5^{-}}$-labeled compounds, the sum of the peak areas of the $\mathrm{D}_{5^{-}}$ and $\mathrm{D}_{6}$-compound was used for quantification.

\section{Extraction and Quantification of GABA}

Similar to phytohormones quantification, $250 \mathrm{mg}$ of fresh tissue from either leaves, bunches, branches, and tendrils (coiled and non-coiled) were frozen in liquid nitrogen and weighed for the determination of GABA content per $g$ fresh weight. The material was homogenized by maceration. Later on, the amino acids (including GABA) were extracted twice with a total of $2 \mathrm{ml}$ of methanol. Supernatants were combined and dried using a Concentrator plus (Eppendorf, Hamburg, Germany) and re-suspended in $500 \mu \mathrm{l}$ of methanol. 
The extract was diluted 1:20 (v/v) with water containing the internal standard. The algal amino acid mix ${ }^{13} \mathrm{C},{ }^{15} \mathrm{~N}$ (Isotec, Miamisburg, USA) was used as a standard at a concentration of $10 \mu \mathrm{g}$ of the algal amino acid mix ml $\mathrm{m}^{-1}$. The content of GABA was analyzed by LC-MS/MS according to previous studies (Scholz et al. 2017). An API 5000 tandem mass spectrometer (Applied Biosystems, Darmstadt, Germany) was operated in positive ionization mode with multiple reaction monitoring (MRM) to monitor analyte parent ion $\rightarrow$ product ion: GABA $(m / z, 104.1 \rightarrow 87.1$; DP 51, CE 17) an MRM specific for GABA. GABA in the sample was quantified using $\mathrm{U}_{-}{ }^{13} \mathrm{C},{ }^{15} \mathrm{~N}$-Ala applying a response factor of 1.0.

\section{Tendril Coiling Assay}

We used tendrils from 20 different plants. The whole experiment was independently performed twice to ensure maximal reproducibility. Each time we incubated ten non-coiled tendrils, five being selected as short ones $(5-6 \mathrm{~cm})$ and five as long ones $(8-10 \mathrm{~cm})$, in water or different solutions containing either GABA (Sigma-Aldrich), 3-mercaptopropionic acid (3-MPA) (Sigma-Aldrich), JA (Sigma-Aldrich), or combinations thereof: (1) deionized water; (2) GABA $(50 \mu \mathrm{M})$; (3) JA $(50 \mu \mathrm{M})$; (4) GABA and JA ( $50 \mu \mathrm{M}$ each); GABA and 3-MPA ( $50 \mu \mathrm{M}$ each); JA and 3-MPA (50 $\mu \mathrm{M}$ each); 3-MPA $(50 \mu \mathrm{M}$ each). After harvesting, the tendrils were directly transferred into the respective solutions. Five Petri dishes, with $20 \mathrm{ml}$ of each solution, were used for incubation of two tendrils per plate, in a total of forty plates in each experimental replicate. The plates were placed in a phytochamber during the time of tendril coiling evaluation. The growth chamber was adjusted to $50-60 \%$ humidity and $21{ }^{\circ} \mathrm{C}$ with a 10-h-light/14-h-dark photoperiod with a light intensity of $100 \mathrm{mmol} \mathrm{m}^{2} \mathrm{~s}^{-1}$. Tendrils were evaluated at $0,5,20,30$, and $48 \mathrm{~h}$; the $0 \mathrm{~h}$ time point was taken immediately after transfer into the solutions. The coiling scale (CS, for clarification see Fig. 1a) was set according to the work of Weiler et al. (1993) and calculated as follows: multiply the number of tendrils in each scale by the percentage of the scale and sum it up, then divide the sum by five sum of scales $(0,25$, 50,75 , and $100 \%$ ), in each time point for each treatment. For example, time point: $0 \mathrm{~h}$, treatment: water, tendrils at $0 \%: 6$, tendrils at $25 \%$ : 4 ; coiling score $=(0 \times 6)+(25 \times 4) / 5=20$.

\section{Statistics}

The statistical analyses are indicated in the respective figure legends. Two-way ANOVA, the Student's test, or a Chisquare test was used. All experiments were repeated two times to ensure reproducibility and 10-20 plants were used in each treatment for each experimental time point. Different letters indicate significant differences between treatments. $\mathbf{a}$
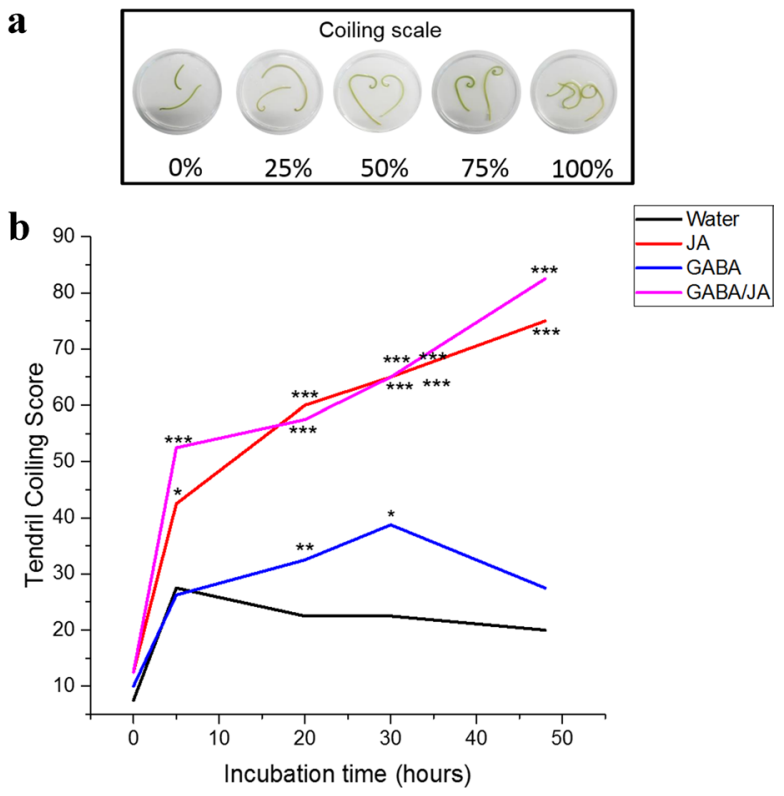

Fig. 1 Tendril coiling abilities of exogenously applied JA and GABA on non-coiled grapevine tendrils at different time points. a Coiling scale for grapevine tendrils. $0 \%=$ no observable effect; $25 \%=$ coiling only at apical, but not basal (cut) end; $50 \%=$ coiling at apical as well as basal (cut) end, but median part straight; $75 \%=$ fully coiled, loose spiral; and $100 \%=$ tendril fully coiled, tight spiral on both ends. Photos were taken at $48 \mathrm{~h}$ after starting the incubation. b Quantitative score on tendril coiling induction upon treatments with water; GABA $(50 \mu \mathrm{M})$; JA $(50 \mu \mathrm{M})$; GABA/JA (50 $\mu \mathrm{M}$ each). Statistically significant differences between treatments and water control were analyzed by Chi-square with four degrees of freedom $(* p \leq 0.05 ; * * p \leq 0.01$; $* * * p \leq 0.001$ ) and found for GABA at $20 \mathrm{~h} \chi^{2}=10.00$; JA at $20 \mathrm{~h}$ $\chi^{2}=62.5 ;$ at $30 \mathrm{~h} \chi^{2}=80.27$; at $48 \mathrm{~h} \chi^{2}=151.25$; GABA/JA at $5 \mathrm{~h}$ $\chi^{2}=22.7$; at $20 \mathrm{~h} \chi^{2}=54.44 ;$ at $30 \mathrm{~h} \chi^{2}=80.27$; at $48 \mathrm{~h} \chi^{2}=195.31$

We used GraphPad Prism 6 and Origin Pro for data analysis and graph composition.

\section{Results and Discussion}

\section{Phytohormone Analysis in Various Grapevine Tissues}

Jasmonates are known to be involved in plant defense against herbivore attack and mechanical wounding but these signaling molecules can also work as regulatory compounds in growth and development of a non-stressed plant (Wasternack 2007). Before specifically addressing the question of whether or not jasmonates might play a role in grapevine tendril coiling, we first determined the general levels of jasmonate-related compounds in different grapevine organs, that is, leaves, bunches, branches, and tendrils. As expected, for leaves, bunches, and branches, we observed some differences in the phytohormones levels, very likely representing tissue-specific characteristics 
(Table 1 and Supplementary Table 1). We next investigated whether the conformation of the tendril-influenced jasmonate levels. For that reason, we sampled two types of grapevine tendrils: (1) tendrils that were already coiled and (2) tendrils that were not coiled, but fully expanded (Supplementary Fig. 1D). For all jasmonates including OPDA, the non-coiled tendrils showed higher (between 2.5- and 7.2-fold) levels than coiled ones (Table 1). The degradation metabolites (OH-JA, OH-JA-Ile and $\mathrm{COOH}-$ JA-Ile) of jasmonates followed the same trend (Supplementary Table 1). These observations can be explained by a certain capacity of non-coiled tendrils to sense the environment and maybe to defend itself from a herbivore attack, whereas a coiled tendril has already fulfilled its main objective of being attached to a support.

We also tested other stress-related hormones, SA and ABA, on the same samples used for jasmonate evaluation. $\mathrm{SA}$ is known to be mainly involved in stress responses against biotrophic and hemibiotrophic pathogens (Grant and Lamb 2006; Bari and Jones 2009). The roles of ABA are vast, from drought stress resistance to regulation of plant development processes (Wasilewska et al. 2008; Bari and Jones 2009). For both phytohormones we observed a kind of tissue-specific distribution for the particular hormones (Table 1). The levels of SA were highest in branches and elevated in tendrils, independently of their coiling conformation. This suggests that stem-related tissues might have a generally high level of SA compared with other tissues. Furthermore, ABA showed smaller differences in the accumulation levels between all tissues evaluated. Bunches and branches presented the highest levels, whereas tendrils and leaves had almost the same ABA concentrations (Table 1). Nevertheless, uncoiled tendrils possess higher concentrations of ABA than coiled ones (Table 1). These results are similar to those observed for jasmonates, in which non-coiled tendrils seem to have a higher amount of defense molecules, which could mean that these structures can be more resilient to biotic and/or abiotic stress. However, Bangerth (1974) stated that ABA beside gibberellins and kinetin did not induce tendril coiling in cucumber (Cucumis sativus).

\section{Tendrils Show Higher GABA Levels}

Another stress-related molecule we analyzed is GABA $(\gamma$-aminobutyric acid). This four-carbon non-proteinogenic amino acid is present in microorganisms, animals, and plants. It acts as an inhibitory neurotransmitter in the mammalian central nervous system by regulating ion channels (Shelp 2012). However, in plants, GABA was reported to be involved in diverse processes, such as influencing cell respiration by regulating the Krebs cycle and acting as a compound for signaling development and growth (Bouché and Fromm 2004; Bown and Shelp 2016). In Arabidopsis and tobacco, optimal pollen, pistil, and root growth were described to be dependent on GABA levels (Mirabella et al. 2008; Renault et al. 2011; Yu et al. 2014). GABA can accumulate in plants upon abiotic stress such as salt and cold (Wallace et al. 1984; Ramputh and Bown 1996). It also was proven to be involved in defense responses against herbivore attack and mechanical wounding in a jasmonate-independent manner (Ramputh and Bown 1996; Scholz et al. 2015; Bown and Shelp 2016). In addition, there is evidence for a GABAinduced GABA accumulation (Scholz et al. 2017).

Thus, we also included GABA in our analyses of grapevine tissues. Our results show that GABA is present in leaves, bunches, and branches in equivalent amounts (Fig. 2). Strikingly, GABA levels were up to fivefold higher in tendrils, with apparently no difference between coiled and non-coiled tendrils. These data suggest that GABA could have a role in tendril development or growth.

\section{Impact of JA and GABA on Tendril Coiling in Grapevine}

To examine the effects of JA and GABA on tendril coiling in grapevine, we performed experiments with non-coiled tendrils that were treated with different solutions of these particular compounds. Thereafter, we applied a coiling scale for the classification of the tendril coiling process (Fig. 1a). Our treatments demonstrate that JA can induce coiling in grapevine tendrils without touching. This effect is visible already after $5 \mathrm{~h}$ (Fig. 1b). We furthermore observed that
Table 1 Phytohormone levels (ng g ${ }^{-1} \mathrm{FW}$ ) in different grapevine tissues

\begin{tabular}{lccllc}
\hline & cis-OPDA & JA & JA-Ile & SA & ABA \\
\hline Leaf & $133 \pm 75.4$ & $9.0 \pm 4.5$ & $0.7 \pm 0.9$ & $63.5 \pm 19.4$ & $354 \pm 105$ \\
Bunch & $158 \pm 90.2$ & $8.5 \pm 5.0$ & $2.3 \pm 1.9$ & $129 \pm 30.8$ & $913 \pm 200$ \\
Branch & $459 \pm 163$ & $32.9 \pm 6.5$ & $0.9 \pm 0.4$ & $1012 \pm 440$ & $894 \pm 150$ \\
Tendril non-coiled & $203 \pm 86^{* *}$ & $30.2 \pm 7.2^{* * *}$ & $2.9 \pm 1.7 * * *$ & $328.4 \pm 72.85 \mathrm{~ns}$ & $559.6 \pm 90.6^{* * *}$ \\
Tendril coiled & $80.3 \pm 49.7^{* *}$ & $7.0 \pm 2.0^{* * *}$ & $0.4 \pm 0.1^{* * *}$ & $294.4 \pm 79.73 \mathrm{~ns}$ & $393.7 \pm 69.98^{* * *}$ \\
\hline
\end{tabular}

Shown are average levels \pm SE ( $n=7$ for leaf, branch, bunch; $n=10$ for tendrils, coiled and non-coiled). Statistically significant differences for the same phytohormones between the tendrils were analyzed by Student's $t$ test: $n s$ non-significant; **p $<0.001 ; * * * p<0.0001$ 


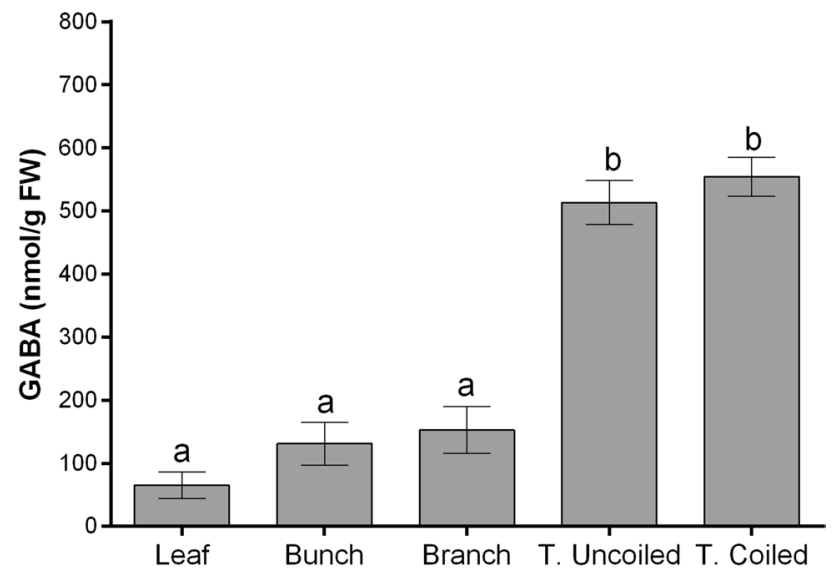

Fig. 2 GABA levels in different grapevine tissues. Fully expanded leaves, bunches in fruit-set stage, non-lignified branches, tendrils (coiled and non-coiled) were analyzed. Shown are average levels \pm SE, $n=7$ for leaf, branch, bunch; $n=10$ for tendrils. Significant differences between the tissues for the samples were analyzed by twoway ANOVA $(p<0.05$, Mann-Whitney-U test) and indicated by different letters. Each individual tendril was harvested from individual plants. Samples were harvested around noon and immediately frozen

after the first $5 \mathrm{~h}$ the JA-induced effect on tendril coiling increased a bit slower but continuously (Fig. 1b). The fast initial coiling phase (between 0 and $5 \mathrm{~h}$ ) that can be seen in all approaches is very likely a result of rapid water uptake and the predetermined tendril anatomy; obviously, in the presence of JA a combined effect of water uptake and JAmediated coiling seems to take place (Fig. 1b). GABA also induced coiling of tendrils without any touch although in the early phase not to the same extent as JA (Fig. 1b). However, between 5 and $30 \mathrm{~h}$ of incubation, the increase of the GABAinduced coiling score is similar to that of JA-induced coiling. Later on, the GABA effect on tendrils faded suggesting that this process is transient and reversible. To get an impression about the distribution of tendrils with respect to the particular CS, we did a more detailed analysis as shown in Fig. 3. In the water control, the majority of the tendrils did belong to 0 and $25 \%$ CS and only a few were found having $50 \%$ CS. Upon GABA treatment, a few tendrils with a $75 \%$ coiling score appeared rapid and transiently while the majority of the tendrils belonged to the 25 and $50 \%$ coiling CS. The latter also disappeared but at later time. JA treatment caused a majority of tendrils with a CS of higher than $50 \%$ already after $20 \mathrm{~h}$. Here, after $30 \mathrm{~h}$, for the first time tendrils with $100 \%$ of CS were detected but never a transient effect (Fig. 3). To find out whether GABA and JA have additive or synergistic effects on tendril coiling, we treated them with a combination of both compounds. Neither additive nor synergistic effects were found. Instead, we observed that only after $5 \mathrm{~h}$ the coiling score was slightly more pronounced due to a higher number of tendrils belonging to $75 \% \mathrm{CS}$. Later on, there were no more clear differences to the treatment

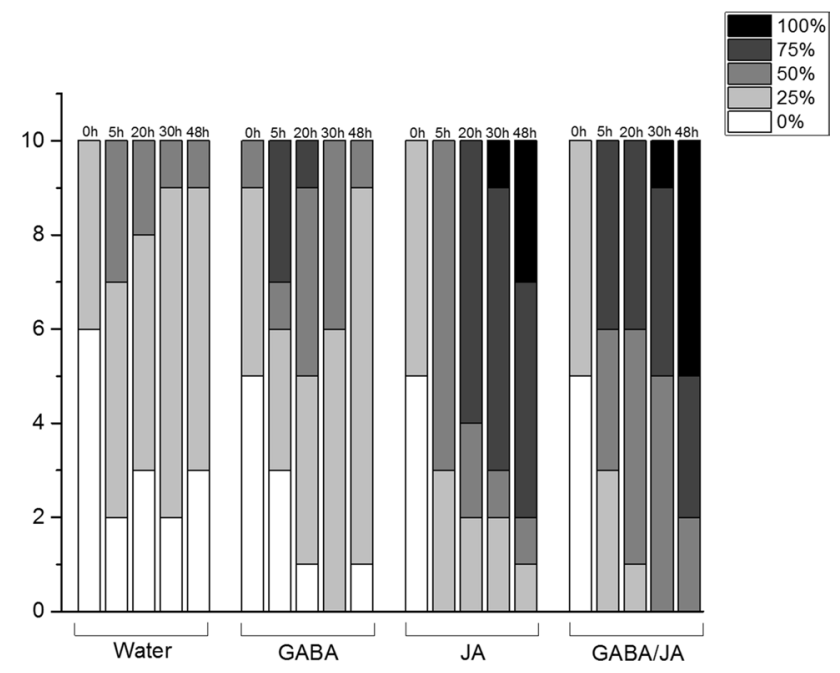

Fig. 3 Distribution of coiled tendrils between the coiling scales (see Fig. 1a) at different time points. Tendril coiling induction upon treatments with water; GABA $(50 \mu \mathrm{M})$; JA $(50 \mu \mathrm{M})$; GABA/JA $(50 \mu \mathrm{M}$ each) with scores based on the tendril coiling scale for grapevine tendrils $(0 \%=$ no observable effect; $25 \%=$ coiling only at apical, but not basal (cut) end; $50 \%=$ coiling at apical as well as basal (cut) end, but median part straight; $75 \%=$ fully coiled, loose spiral; and 100\% =tendril fully coiled, tight spiral on both ends)

with JA alone (Figs. 1b, 3). However, still an open question is whether cutting of the tendrils might induce a higher jasmonate level, which in turn could prime the tendril tissue towards GABA sensitivity and GABA-induced coiling response. This possibility will be tested in further experiments using GABA and/or JA on intact tendrils.

To further evaluate the effects of GABA on grapevine tendrils, we tested if its absence would affect tendril coiling by applying 3-MPA. This compound was described first to inhibit the GABA-generating enzyme glutamate decarboxylase (GAD) in vitro and in vivo, causing a decrease in GABA content in rat brains (Lamar 1970; Karlsson et al. 1974). In plants, the application of $50 \mu \mathrm{M}$ 3-MPA was shown to affect GABA synthesis, causing an abnormal formation of pollen tubes due to the disruption of actin organization in these organs. With higher amounts (2 mM), 3-MPA completely inhibited pollen germination (Yu et al. 2014). Using $50 \mu \mathrm{M}$ 3-MPA, our results show that the GABA-induced tendril coiling score was significantly reduced by the inhibitor after 20 and $30 \mathrm{~h}$ (Fig. 4). This seems to conflict with the inhibitory effect of 3-MPA on GABA synthesis. However, the work of Scholz et al. (2017) demonstrated a GABA-induced endogenous GABA accumulation in Arabidopsis leaves. Thus, applying GABA from outside would also increase GABA synthesis in tendrils, which will be inhibited in the presence of 3-MPA. Moreover, treatment with 3-MPA alone reduced the coiling score at the same time points compared with the water 


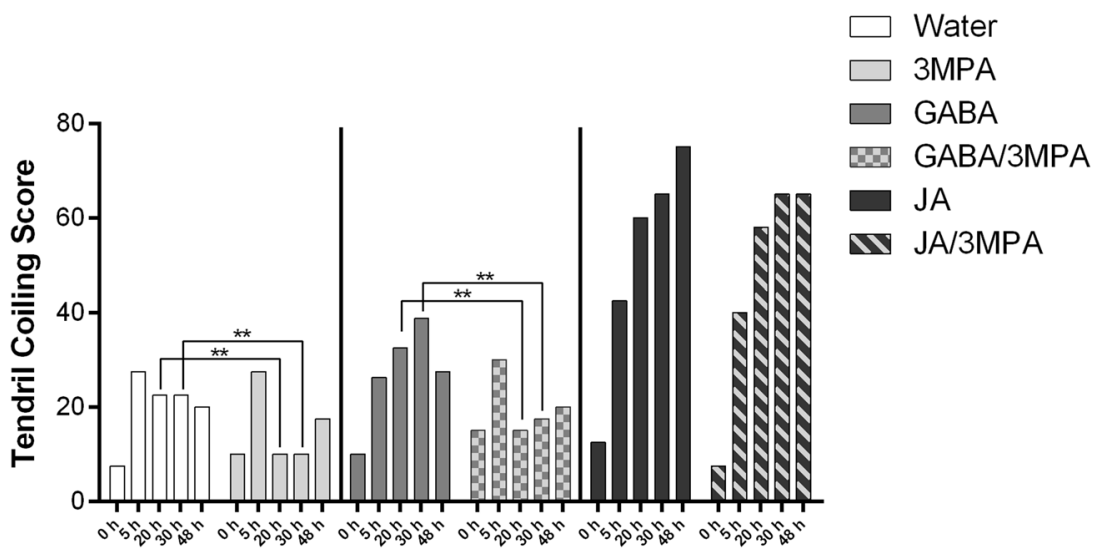

Fig. 4 Effect of 3-MPA on GABA-mediated coiling induction on grapevine tendrils at different time points. Coiling score was determined upon treatments with water; 3-MPA $(100 \mu \mathrm{M})$; GABA $(50 \mu \mathrm{M})$; GABA/3-MPA $(50 \mu \mathrm{M} / 100 \mu \mathrm{M})$; JA $(50 \mu \mathrm{M})$; and JA/3MPA $(50 \mu \mathrm{M} / 100 \mu \mathrm{M})$. Statistically significant differences between

control (Fig. 4). Both results suggest that a continuous synthesis of GABA seems necessary for tendril coiling. Interestingly, when 3-MPA was applied along with JA it reduced the effect of JA only slightly after $48 \mathrm{~h}$ (Fig. 4) suggesting that 3-MPA indeed affects the GABA pathway and does not have a non-specific effect on tendril coiling. Because of the selective effect of 3-MPA together with the finding that there is no combined effect of JA and GABA (Fig. 1b), it is tempting to speculate that both compounds act independently. A similar observation was made before in Arabidopsis plants, which were challenged with herbivores (Scholz et al. 2015).

Taken together, our results show that JA has a strong impact on grapevine tendril coiling, similar to what has been described for B. dioica tendrils (Blechert et al. 1999; Stelmach et al. 1999). Moreover, also for GABA tendril coilinginducing activity could be shown. Although the JA effect was progressive and more pronounced, the GABA effect was weaker and transient. Whether and how both signaling compounds may act together or independently from each other remains an open question and will be addressed in further studies.

Acknowledgements Open access funding provided by Max Planck Society. We thank Wilhelm Boland and the Max Planck Society and Celia R. Carlini for support. We also want to thank Friederike Wagner who kindly provided access to her vineyard in Freyburg. This work was further supported in part by the German Academic Exchange Service (DAAD; PPP Project ID 57142556) and by the Brazilian agency Coordenadoria de Aperfeiçoamento de Pessoal de Nível Superior (CAPES), Program PROBRAL 407/2016, Grant 23038.006810/2014-51. treatments were analyzed by Chi-square with four degrees of free$\operatorname{dom}(* * p<0.001)$. Water $X 3$-MPA at $20 \mathrm{~h} \chi^{2}=15.625$ and at $30 \mathrm{~h}$ $\chi^{2}=15.625$; GABA X GABA/3-MPA at $20 \mathrm{~h} \chi^{2}=9.423$ and at $30 \mathrm{~h}$ $\chi^{2}=11.653$

Author Contributions JM and AM conceived and designed the research; JM, MR, GP, and AM performed the experiments; JM and AM wrote the manuscript. All authors contributed to the manuscript.

\section{Compliance with Ethical Standards}

Conflict of interest The authors declare that the research was conducted in the absence of any commercial or financial relationships that could be construed as a potential conflict of interest.

Open Access This article is distributed under the terms of the Creative Commons Attribution 4.0 International License (http://creativeco mmons.org/licenses/by/4.0/), which permits unrestricted use, distribution, and reproduction in any medium, provided you give appropriate credit to the original author(s) and the source, provide a link to the Creative Commons license, and indicate if changes were made.

\section{References}

Bangerth F (1974) Interaktionen von Auxin und Äthylen bei der thigmotropen Bewegung der Ranken von Cucumis sativus. Planta 117:329-338. https://doi.org/10.1007/BF00388027

Bari R, Jones JDG (2009) Role of plant hormones in plant defence responses. Plant Mol Biol 69:473-488. https://doi.org/10.1007/ s11103-008-9435-0

Blechert S, Bockelmann C, Füßlein M et al (1999) Structure-activity analyses reveal the existence of two separate groups of active octadecanoids in elicitation of the tendril-coiling response of Bryonia dioica Jacq. Planta 207:470-479. https://doi.org/10.1007/s0042 50050506

Bouché N, Fromm H (2004) GABA in plants: Just a metabolite? Trends Plant Sci 9:110-115. https://doi.org/10.1016/j.tplants.2004.01.006

Bowling AJ, Vaughn KC (2009) Gelatinous fibers are widespread in coiling tendrils and twining vines. Am J Bot 96:719-727. https:// doi.org/10.3732/ajb.0800373 
Bown AW, Shelp BJ (2016) Plant GABA: not just a metabolite. Trends Plant Sci 21:811-813. https://doi.org/10.1016/j.tplan ts.2016.08.001

Braam J (2004) In touch—plant responses to mechanical stimuli. New Phytol 165:17. https://doi.org/10.1111/j.1469-8137.2004.01263.x

Darwin C (1865) On the movements and habits of climbing plants. Bot J Linn Soc 9: 1-118

Engelberth J (2003) Mechanosensing and signal transduction in tendrils. Adv Space Res 32:1611-1619

Falkenstein E, Groth B, Mithöfer A, Weiler EW (1991) Methyljasmonate and $\alpha$-linolenic acid are potent inducers of tendril coiling. Planta 185:316-322. https://doi.org/10.1007/BF00201050

Fukano Y, Yamawo A (2015) Self-discrimination in the tendrils of the vine Cayratia japonica is mediated by physiological connection. Proc R Soc Lond 282:20151379. https://doi.org/10.1098/ rspb.2015.1379

Grant M, Lamb C (2006) Systemic immunity. Curr Opin Plant Biol 9:414-420. https://doi.org/10.1016/j.pbi.2006.05.013

Isnard S, Silk WK (2009) Moving with climbing plants from Charles Darwin's time into the 21st century. Am J Bot 96:1205-1221. https://doi.org/10.3732/ajb.0900045

Jaffe MJ, Galston AW (1968) The physiology of tendrils. Annu Rev Plant Physiol 19(1):417-434

Jaffe MJ, Leopold AC, Staples RC (2002) Responses in plants and fungi. Am J Bot 89:375-382. https://doi.org/10.3732/ajb.89.3.375

Karlsson A, Fonnum F, Malthe-Sørenssen D, Storm-Mathisen J (1974) Effect of the convulsive agent 3-mercaptopropionic acid on the levels of GABA, other amino acids and glutamate decarboxylase in different regions of the rat brain. Biochem Pharmacol 23:3053-3061

Lacirignola C, Digiaro M (1999) Grapevine industry in the world: state of the art and future trends. In: Martelli G.P. (ed.), Digiaro M. (ed.). Proceedings of the Mediterranean network on grapevine closteroviruses 1992-1997 and the viroses and virus-like diseases of the grapevine a bibliographic report, 1985-1997. Bari: CIHEAM, 1999. p. 33-46. (Options Méditerranéennes : Série B. Etudes et Recherches; n. 29). Mediterranean Network on Grapevine Closteroviruses (1992-1997) 46:33-46

Lamar C (1970) Mercaptopropionic acid: a convulsant that inhibits glutamate decarboxylase. J Neurochem 17(2):165-170

Mirabella R, Rauwerda H, Struys EA et al (2008) The Arabidopsis her1 mutant implicates GABA in E-2-hexenal responsiveness. Plant $\mathrm{J}$ 53:197-213. https://doi.org/10.1111/j.1365-313X.2007.03323.x

Pratt C (1971) Reproductive anatomy in cultivated grapes. A review. Am J Enol Vitic 22:91-109

Ramputh A, Bown A (1996) Rapid $\gamma$-aminobutyric acid synthesis and the inhibition of the growth and development of oblique-banded leaf-roller larvae. Plant Physiol 8:6-9

Renault H, El Amrani A, Palanivelu R et al (2011) GABA accumulation causes cell elongation defects and a decrease in expression of genes encoding secreted and cell wall-related proteins in
Arabidopsis thaliana. Plant Cell Physiol 52:894-908. https://doi. org/10.1093/pcp/pcr041

Scholz SS, Reichelt M, Mekonnen DW et al (2015) Insect herbivoryelicited GABA accumulation in plants is a wound-induced, direct, systemic, and jasmonate-independent defense response. Front Plant Sci 6:1128. https://doi.org/10.3389/fpls.2015.01128

Scholz SS, Malabarba J, Reichelt M et al (2017) Evidence for GABA-induced systemic GABA accumulation in Arabidopsis upon wounding. Front Plant Sci 8:1-9. https://doi.org/10.3389/ fpls.2017.00388

Shelp BJ (2012) Does long-distance GABA signaling via the phloem really occur? Botany 90:897-900. https://doi.org/10.1139/b2012 $-066$

Srinivasan C, Mullins MG (1979) Flowering in Vitis: conversion of tendrils into inflorescences and bunches of grapes. Planta 145:187192. https://doi.org/10.1007/BF00388716

Stelmach BA, Müller A, Weiler EW (1999) 12-Oxo-phytodienoic acid and indole-3-acetic acid in jasmonic acid-treated tendrils of Bryonia dioica. Phytochemistry 51:187-192. https://doi.org/10.1016/ S0031-9422(99)00017-5

This P, Lacombe T, Thomas MR (2006) Historical origins and genetic diversity of wine grapes. Trends Genet 22:511-519. https://doi. org/10.1016/j.tig.2006.07.008

Vadassery J, Reichelt M, Hause B et al (2012) CML42-mediated calcium signaling coordinates responses to Spodoptera herbivory and abiotic stresses in Arabidopsis. Plant Physiol 159:1159-1175. https://doi.org/10.1104/pp.112.198150

Wallace W, Secor J, Schrader LE (1984) Rapid accumulation of gamma-aminobutyric acid and alanine in soybean leaves in response to an abrupt transfer to lower temperature, darkness, or mechanical manipulation. Plant Physiol 75:170-175. https://doi. org/10.1104/pp.75.1.170

Wasilewska A, Vlad F, Sirichandra C et al (2008) An update on abscisic acid signaling in plants and more. Mol Plant 1:198-217. https ://doi.org/10.1093/mp/ssm022

Wasternack C (2007) Jasmonates: an update on biosynthesis, signal transduction and action in plant stress response, growth and development. Ann Bot 100:681-697. https://doi.org/10.1093/ $\mathrm{aob} / \mathrm{mcm} 079$

Weiler EW (1997) Octadecanoid-mediated signal transduction in higher plants. Naturwissenschaften 84(8):340-349

Weiler EW, Albrecht T, Groth B et al (1993) Evidence for the involvement of jasmonates and their octadecanoid precursors in the tendril coiling response of Bryonia dioica. Phytochemistry 32:591600. https://doi.org/10.1016/S0031-9422(00)95142-2

Yu GH, Zou J, Feng J et al (2014) Exogenous $\gamma$-aminobutyric acid (GABA) affects pollen tube growth via modulating putative $\mathrm{Ca}^{2+}$-permeable membrane channels and is coupled to negative regulation on glutamate decarboxylase. J Exp Bot 65:3235-3248. https://doi.org/10.1093/jxb/eru171 